\title{
Cenozoic bi-polar connections over millennia
}

\section{Session and town meeting at 33rd International Geological Congress Oslo, Norway, August 2008}

\section{Julie Brigham-Grette ${ }^{1}$ and Ross D. Powell ${ }^{2}$}

'Department of Geosciences, University of Massachusetts, Amherst, USA; juliebg@geo.umass.edu

${ }^{2}$ Department of Geology and Environmental Geosciences and Analytical Center for Climate and Environmental Change, Northern Illinois University, DeKalb, USA

Several innovative geological drilling projects (e.g., Arctic Coring Expedition (ACEX), Lake El'gygytgyn, ANDRILL (Antarctic Drilling Project), SHALDRIL (Shallow Drilling on the Antarctic Continental Margin) in the polar regions are in the process of recovering long sedimentary records of climate and environmental change for the past hundreds to millions of years. Syntheses and inter-comparative assessments of these records are required for better understanding of polar climate drivers and linkages, and science plans need to be established in order to evaluate conflicting interpretations of those comparative syntheses. The focus of this session at the $33^{\text {rd }}$ IGC was to assess the initial results of these drilling projects and place them in a global context. The session was advertised and solicited as an International Polar Year contribution to the Bipolar Climate Machinery (BIPOMAC) and Antarctic Climate Evolution (ACE) programs.

Lively presentations and discussions emphasized the global nature of late Cenozoic (ca. 40 Myr ago) change, espe-

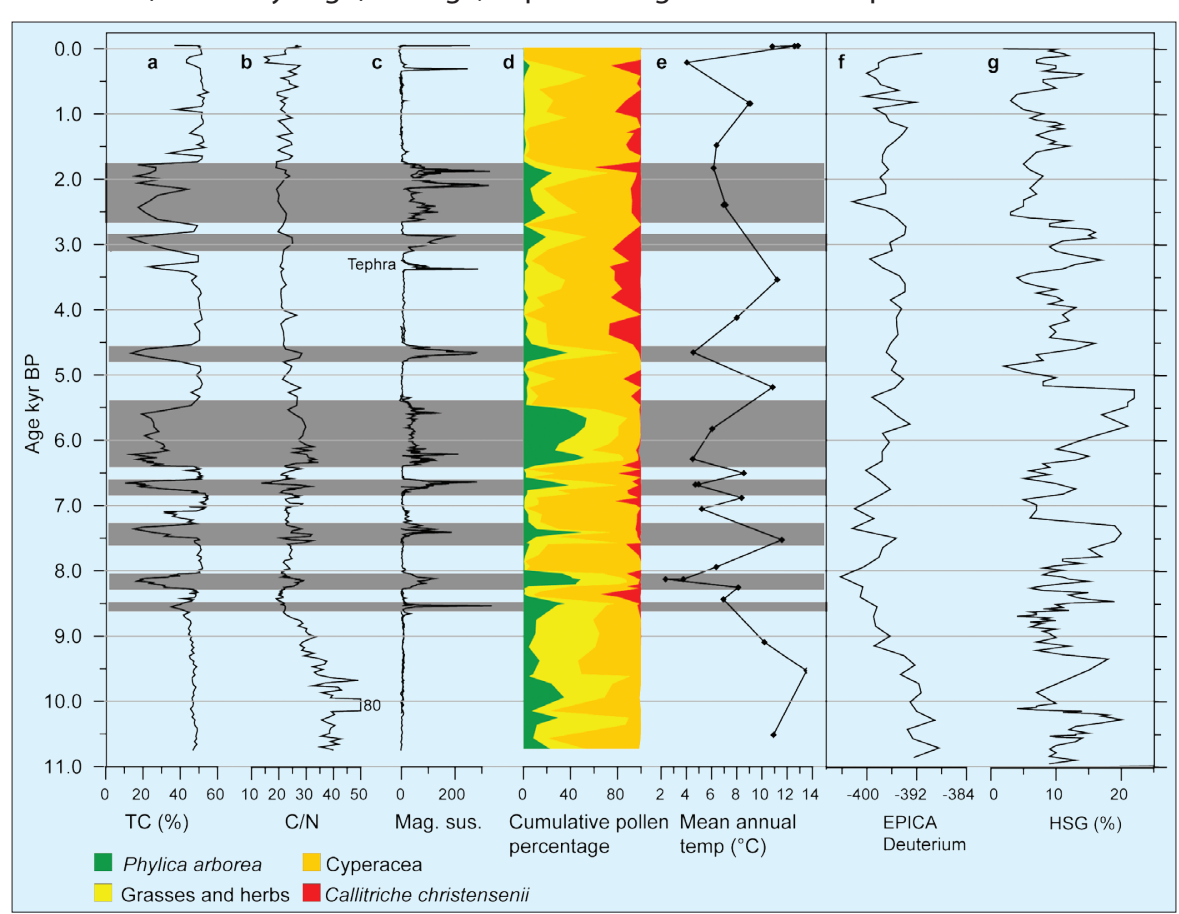

Figure 1: $\boldsymbol{a}$-d) Total carbon, carbon-nitrogen ratio, magnetic susceptibility, cumulative pollen percentages (Ljung and Björck, 2007) and e) mean annual temperatures (unpublished data) from a lake on Nightingale Island (37 $\left.{ }^{\circ} \mathrm{S}\right)$ in the central South Atlantic. The temperature reconstructions are inferred from the methylation index of branched tetraethers (MBT) using the calibration of Weijers et al. (2007). f) Deuterium from the EPICA ice core as an indicator of temperature (Epica Community Members, 2004), and $\boldsymbol{g}$ ) percentage of hematite stained grains (HSG) from marine cores in the North Atlantic, as an indicator of ice rafting (Bond et al., 2001). Gray bars denote periods with increased erosion caused by increased precipitation on Nightingale Island. The Nightingale proxy data reveal a variable Holocene climate, with temperature and precipitation changes probably caused by variations of the southern hemisphere Westerlies and South Atlantic sea surface temperatures.

cially the timing and magnitude of past climatic events on orbital and millennial both poles. Provocative assessments were made on the role the polar regions play in driving and amplifying global variability, and in interpreting the co-evolution of polar paleoenvironments.

Keynote talks introduced and summarized each of the major completed and planned polar drilling projects; there were five presentations each for Antarctic and Arctic science, and one relating South Atcords included papers led by Moran, Stickley, Sangiorgi and Krupskaya, focusing on results from the ACEX drilling project. These presentations included a general overview of a dynamic Arctic Ocean, bio-
genic silica productivity in the Middle Eocene (ca. 40 Myr ago), surface water temperature estimates from Tex86 that differ from iceberg rafting inferences made from sedimentology, and Arctic weathering regimes inferred from clay mineralogy. Brigham-Grette explained the conflict in

(a) 